uous honeycomb interface between the two phases.

A similar mechanism could be involved in the transformation of layered materials such as kaolin to three-dimensionally periodic networks such as ultramarine. If the sandwich layers are closer than some critical distance, unstable tubes like those

\title{
Population dynamics
}

\section{More time means more variation}

\section{John H. Lawton}

UNDERSTANDING patterns in the amplitude and frequency of population fluctuations is one of the central problems in ecology ${ }^{1-3}$. Why do some populations fluctuate very little, whereas others vary wildly? Why do a minority of populations vary cyclically when the majority show no clear periodicity, and so on? Implicit in these questions is the assumption that the variation itself is easy to measure and hence that characteristic levels of population variation can be defined for various taxa ${ }^{3-5}$. However, as Pimm and Redfearn show ${ }^{6}$ on pages $613-614$ of this issue, quantifying the variation itself is not a straightforward problem. The longer you observe a population, the more variable it seems to be. This simple fact has important theoretical and practical implications.

Pimm and Redfearn examined data from a large number of terrestrial animal populations (4 species of insects and 26 of birds and mammals) from censuses taken at least annually for over 50 years, plus information on 42 species of farmland birds and 32 species of woodland birds spanning 24 years, gathered by the British Trust for Ornithology. They measured population variation as the standard deviation of the logarithms of annual densities $^{3.7}$, and applied this measure to increasingly long segments of the counts for each population $(2,4,8$ years and so on). In most cases, more time meant more variation, right up to the maximum length of the time series. Very roughly, populations observed over 20 or 30 years seem to be twice as variable as populations studied for just 2 or 3 years (see figure).

As the authors point out, an explanation for this observation almost certainly resides in the nature of environmental variation. Environmental disturbances, such as hard winters, fires and unusually good summers, that buffet or boost populations irrespective of density - the socalled density-independent processes ${ }^{1-3}$ are a major cause of population fluctuaon page 600 of this issue could grow between the surfaces to minimize the interfacial area.

Alan L. Mackay is in the Department of Crystallography, Birkbeck College, London WCIE $7 H X, U K$. shown in Thomas and co-workers' Fig. $3 a$ tions. We are all familiar with the idea that the further two places are apart in space, the less similar will be their environments: Chicago and Calgary have different climates but they are more similar to one another than either is to Calcutta. It is perhaps not so immediately obvious that the same is true at one place through time $^{8}$. Mathematically, this is the same as saying that environmental variation at one place has a reddened spectrum. The term
Redfearn's observations ${ }^{6}$ have several important theoretical and practical implications. For example, work on comparative population variability ${ }^{4.5,9}$ will be much more difficult to interpret if it mixes studies that differ in duration. Second, do all populations continue to get more variable as time goes on or does variation level out? A truly reddened spectrum would imply that variation increases inexorably over time. Yet there are signs in Pimm and Redfearn's data that variation rises asymptotically to a maximum, at least in some populations. One possibility is that intrinsic stabilizing mechanisms (densitydependent processes) can constrain population variation, at least for a time, before eventually being overwhelmed. The fate of all populations is ultimate extinction.

The implications for conservation biology are profound. An increasing proportion of the exciting and beautiful animals in the world are confined to fragments of their former range in reserves and national parks and we need urgently to know whether these small, remnant populations are viable in the long run. A key parameter in increasingly sophisticated models used to predict minimum viable population sizes" is the variance $r$, that is, in the intrinsic rate of increase. Existing models assume that environmental variation driving variation in $r$ takes particular, average values; but, as we now know, it would be much more realistic to assume that environmental variation increases over time. In other words, minimum viable populations calculated using a reddened spectrum for environmental noise must inevitably be bigger than current estimates based on constant variation. For many species, the long-term urvival of small, isolated populations looks bleak indeed.

1. Krebs, C.J. Ecology. The Experimental Analysis of Distribution and Abundance (Harper \& Row, New York, 1985).

2. May, R.M. (ed.) Theoretical Ecology. Principles and Applications (Blackwell, Oxford, 1981).

3. Williamson, M. The Analysis of Biological Populations (Arnold, London, 1972).

4. Hassell, M.P., Lawton, J.H. \& May, R.M. J. anim. Ecol. 45, 471-486 (1976)

5. Connell, J.H. \& Sousa, W.P. Am. Nat. 121, 789-824 (1983).

6. Pimm, S.L. \& Redfearn, A. Nature 334, 613-614 (1988)

7. Williamson, M. Ecol. Ent. 9, 239-241 (1984).

8. Williamson, M. in Colonization, Succession and Stability (eds Gray, A.J., Crawley, M.J. \& Edwards, P.J.) 353-371 (Blackwell, Oxford, 1987).

9. Gaston, K.J. \& Lawton, J.H. Nature 331, 709-712 (1988)

10. Redfearn, A.\& Pimm, S.L. Ecol. Monogr 58, 39-55 (1988).

11. Belovsky, G.E. in Viable Populations for Conservation (ed. Soulé, M.E.) 35-57 (Cambridge University Press, 1987).

12. Reynolds, C.M. Bird Study 26, 7-12 (1979). extreme excursions in density, driven by increasingly extreme density-independent perturbations.

Intrinsic interest aside, Pimm and
John H. Lawton is a professor in the Department of Biology, University of York, York YOI $5 D D, U K$. 